Original Research Article

\title{
Assessment of undergraduates' preferences and opinions on teaching of Pharmacology
}

\author{
B. B. Bukar*, K. D. Falang, S. S. Gyang
}

Department of Pharmacology and Toxicology, University of Jos, P.M.B. 2084, Jos, Plateau State, Nigeria

Received: 20 November 2017 Accepted: 28 December 2017

\section{*Correspondence to:}

Dr. B. B. Bukar,

Email: bukata33@yahoo.com

Copyright: (C) the author(s), publisher and licensee Medip Academy. This is an openaccess article distributed under the terms of the Creative Commons Attribution NonCommercial License, which permits unrestricted noncommercial use, distribution, and reproduction in any medium, provided the original work is properly cited.

\begin{abstract}
Background: The preference and opinion of undergraduate students on teaching of pharmacology was assessed using structured-based questionnaires. The objective was to determine the best way to teach pharmacology and the areas the students prefer most.

Methods: The questionnaires were administered to students during academic sessions in any of their pharmacology lectures by the help of technical assistants. It was also ensured that the identity of the students was not made known except for the gender. A total of 8 questions with options ranging from 2-4 were used. Each respondent was to select only one option as the most preferred. A total of 405 students participated during the study period and it was ensured that no student participated more than once. The students recruited were 4th and 5th year medical and pharmacy students of the University of Jos, Jos, Nigeria for the 2014/2015 and 2015/2016 academic sessions.

Results: The results showed that the students have high preference for latest technology teaching aids such as power point presentation and use of software for lecture notes.

Conclusions: Knowledge of pharmacodynamics, clinical pharmacology and laboratory experiment were preferred and significant differences exist between observed and expected results and also between males and females in preferences among some of the options. Students need to be informed at the beginning of their lectures that pharmacology is a subject that must be regarded as a whole with no areas of preference.
\end{abstract}

Keywords: Assessment, Feedback, Preference, Pharmacology, Teaching methods, Undergraduate students

\section{INTRODUCTION}

In attempting to make learning easier, different teaching methods have evolved over the years. ${ }^{1}$ Feedback from students has been regarded as one of the best ways to understand the effectiveness of a teaching process. $^{2}$ Different methods have therefore been employed to improve on the effectiveness of teaching and also to enhance accurate delivery of the subject content. ${ }^{3}$

The teaching method has been identified to fundamentally comprise of the principles and methods used by tutors to enable learning by students. ${ }^{4}$ There exist various strategies that are used which are mainly based on the course of study as well as the students. For this reason, over 150 teaching methods have been identified including lecturing, demonstrating, collaborating, class discussions, assignments, notebooks, use of slides, experimental reports among many others. Similarly, there exists different teaching styles. ${ }^{5}$ An effective teaching style is said to engage students in the learning process to help them develop critical thinking skills. Some of these styles include the authority or lecture, demonstration, facilitation, delegation and hybrid or blended styles. ${ }^{6}$ These are broadly categorized into two models, namely, the teacher-centred or the passive traditional didactic approach where the teacher is the main authority and the 
students are to passively receive information through lectures and the student-centred approach model where both the teacher and the student play equally active role. ${ }^{6}$

Pharmacology is a course undertaken by different students of health-related professions mainly medicine, pharmacy, nursing and medical laboratory science. Knowledge of Pharmacology essentially involves teaching and learning of drugs. It has been observed that the existence of numerous drugs with a lot of similarities among them in their characteristics have made the teaching and learning of pharmacology somewhat difficult over the years. Consequently, evolving teaching methods that appear to have replaced the traditional chalk and board-based method have been introduced to facilitate accurate delivery of content and learning in pharmacology. ${ }^{8-12}$

Closely tied to the teaching method are the issues of scope and effective delivery of the syllabus content because pharmacology is a multi-component subject that deals with both the drug and the human condition the drugs are to ameliorate. Pharmacology as a complex subject involves the aspects of theoretical, practical or experimental and clinical procedures that most often lead to information overload. ${ }^{7,13}$ The theoretical aspect deals essentially with ideas concerning drug actions, the practical for understanding of drug action and the clinical for understanding treatments with drugs. Pharmacology components are most often broadly categorized into two main branches, namely, pharmacodynamics and pharmacokinetics.

Pharmacology, being an applied science and a biomedical discipline is essentially taught at the higher level (clinical) of training of undergraduates of the health-related professions. Consequently, it is reported that a good knowledge of pharmacology is of great importance in the development of proficient and competent health personnel such as Doctors and Pharmacists. ${ }^{14}$ Some useful studies that centered on methods of teaching and effective learning in pharmacology have been reported. ${ }^{15,16}$

The aim of the present study was to assess the preferences and opinions of undergraduate students in pharmaceutical and medical sciences of the University of Jos, Jos, Nigeria on the methods and scope of pharmacology being taught them and whether theses preferences or opinions are the same or not between the female and male students. The findings could serve as a feedback for possible improvement on teaching of pharmacology.

\section{METHODS}

In this assessment, the participants were the $4^{\text {th }}$ and $5^{\text {th }}$ year undergraduate students of Pharmacy and Medicine of the University of Jos, Jos, for the 2014/2015 and 2015/2016 academic sessions. The mean age of the students was $24.03 \pm 3.81$ and they hailed from different geographical regions of the country. There was only one international student among them. The assessment was arranged during a pharmacology lecture in second semester of each session.

Based on written structured and validated questionnaires, feedback was obtained by giving a questionnaire to each student to fill according to the options provided. The questionnaires consisted of eight questions with closedended options ranging from 2-4 items. The questions covered essentially areas in teaching aids and scope of pharmacology. For some ethical considerations, the questionnaires were administered by some technical staff of the Department in order to hide the identity of the researchers or any lecturer involved in the teaching of pharmacology in the Department to avoid bias in choices by the respondents. In a similar vein, the questionnaires did not provide options for a student's identity such as name or matriculation number apart from gender for same reason. A total of four hundred and five (405) students were involved.

\section{Statistical analysis of data}

The data were collated and subjected to some statistical analyses using mainly the Chi square test of goodness of fit at a critical significant level of probability, $p=0.05$.

\section{RESULTS}

A total of 405 questionnaires were administered and all were filled and returned with two defaults. This gave an effective response of $99.5 \%$.

\section{Distribution of participants by gender}

Table 1 shows the total number of students and their distribution by gender. Two respondents defaulted by ticking both columns for male and female. These were considered invalid for the rest of the analysis thereby reducing the total to 403 respondents.

Table 1: Total number of respondents.

\begin{tabular}{|lll|}
\hline Description & Number & $\%$ \\
\hline Females & 134 & 33.08 \\
\hline Males & 269 & 66.42 \\
\hline Default & 2 & 0.50 \\
\hline Total & 405 & 100 \\
\hline
\end{tabular}

\section{Preference for best teaching methods in pharmacology}

The result on responses for preferences on best teaching methods in pharmacology is shown on Table 2. The result showed that "combination of all the methods" was highest $(55.8 \%)$ while the "blackboard method" was lowest $(1.7 \%)$. A total of 8 responses $(2.0 \%)$ were either invalid by reason of blank response or multiple choices. More females $(65.0 \%$, ) preferred the "combination method" compared with the males $(51.3 \%)$, while more males $(40.9 \%)$ preferred the "power point presentation method" 
compared with the females $(24.6 \%)$. Generally, there was significant difference in preferences between males and females and between observed and expected results $\left(\chi_{\mathrm{df}}^{2}=3\right.$ $=9.1058, \mathrm{p}<0.05)$.

Table 2: Responses on best teaching methods in pharmacology.

\begin{tabular}{|lllll|}
\hline Option & Females & Males & Total & $\%$ \\
\hline $\begin{array}{l}\text { Dictating } \\
\text { notes }\end{array}$ & $8(6.0)$ & $12(4.5)$ & 20 & 5.0 \\
\hline $\begin{array}{l}\text { Blackboard } \\
\text { notes }\end{array}$ & $1(0.7)$ & $6(2.2)$ & 7 & 1.7 \\
\hline Power point & $33(24.6)$ & $110(40.9)$ & 143 & 35.5 \\
\hline $\begin{array}{l}\text { Combination } \\
\text { of all }\end{array}$ & $87(65.0)$ & $138(51.3)$ & 225 & 55.8 \\
\hline Default & $5(3.7)$ & $3(1.1)$ & 8 & 2.0 \\
\hline Total & 134 & 269 & 403 & 100 \\
\hline
\end{tabular}

Values in parenthesis are \% based on gender for each option

\section{Opinions on lecture notes in pharmacology}

Figure 1 shows the result for opinion of respondent's preference on lecture notes in pharmacology. More respondents generally prefer software lecture materials (61.0\%, consisting of $43.3 \%$ males and $17.7 \%$ females) than taking notes during lectures (39.0, consisting of $24.3 \%$ males and $14.7 \%$ females). A total of 8 respondents (2.0\%) defaulted. More females (45.3\%) prefer taking notes during lecture compared with the males $(36.0 \%)$. Both preferences were below average (50\%). However, on the other hand, more males $(64.0 \%)$ prefer software lecture materials compared with the females $(54.7 \%)$, with both being above average. There was no significant difference in preferences between males and females and between observed and expected results $\left(\chi_{\mathrm{df}=1}^{2}=3.8410, \mathrm{p}>0.05\right)$.

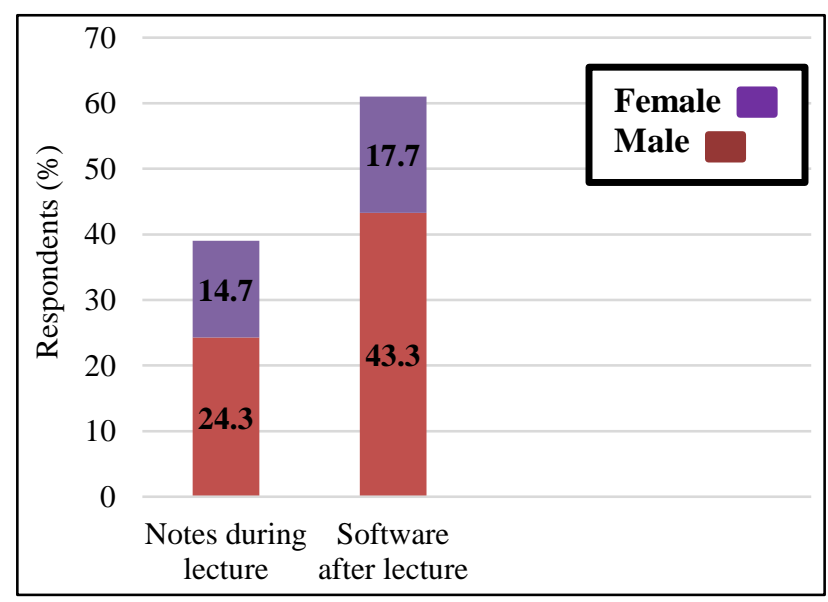

Figure 1: Preference for type of lecture notes.

\section{Preference for lecture sessions in pharmacology}

Table 3 shows the result for preference on lecture sessions in pharmacology by respondents. More respondents generally prefer laboratory experiments or practical sessions $(56.6 \%)$ than classroom theory lectures $(35.0 \%)$. A total of 14 respondents $(8.4 \%)$ defaulted. More females $(38.8 \%)$ prefer classroom theory lecture compared with the males $(33.1 \%)$. Both preferences were below average $(50 \%)$. However, and on the other hand, more males $(59.5 \%)$ prefer laboratory practical compared with the females $(50.7 \%)$, with both being above average. There was no significant difference in preference between males and females and between observed and expected results $\left(\chi_{\mathrm{df}=1}^{2}=1.8816, \mathrm{p}>0.05\right)$.

Table 3: Preference on category of lecture sessions.

\begin{tabular}{|lllll|}
\hline $\begin{array}{l}\text { Lecture } \\
\text { session }\end{array}$ & Females & Males & Total & $\%$ \\
\hline $\begin{array}{l}\text { Classroom } \\
\text { Theory }\end{array}$ & $52(38.8)$ & $89(33.1)$ & 141 & 35.0 \\
\hline $\begin{array}{l}\text { Laboratory } \\
\text { Practical }\end{array}$ & $68(50.7)$ & $160(59.5)$ & 228 & 56.6 \\
\hline Default & $14(10.5)$ & $20(7.4)$ & 34 & 8.4 \\
\hline Total & 134 & 269 & 403 & 100 \\
\hline
\end{tabular}

Values in parenthesis are \% based on gender for each option

\section{Responses on preferred duration of lectures in pharmacology}

The result on responses for preference on duration of lectures in pharmacology is shown on Table 4 . The results showed that 2 hours was highest $(63.0 \%)$ while 3 hours was lowest $(1 \%)$. A total of 2 respondents $(0.5 \%)$ defaulted. The detailed results showed that more males $(37.2 \%)$ preferred a 1-hour lecture compared with the females $(32.1 \%$ ), with both being below average of $50 \%$. On the other hand, more females $(64.9 \%)$ preferred a $2-$ hour lecture compared with the males $(62.1 \%)$, with both being above average. Generally, there was no significant difference in preference between males and females and between observed and expected results $\left(\chi_{\mathrm{df}=2}^{2}=2.0004\right.$, $\mathrm{p}>0.05$ ).

Table 4: Preferred duration for lectures.

\begin{tabular}{|lllll|}
\hline $\begin{array}{l}\text { Duration } \\
\text { (hours) }\end{array}$ & Females & Males & Total & $\%$ \\
\hline 1 & $43(32.1)$ & $100(37.2)$ & 143 & 35.5 \\
\hline 2 & $87(64.9)$ & $167(62.1)$ & 254 & 63.0 \\
\hline 3 & $2(1.5)$ & $2(0.7)$ & 4 & 1.0 \\
\hline Default & 2 & 0 & 2 & 0.5 \\
\hline Total & 134 & 269 & 403 & 100 \\
\hline
\end{tabular}

Values in parenthesis are \% based on gender for each option

\section{Preference on some scopes of pharmacology lectures}

Figure 2 shows the responses of the students on their preference for some scopes of pharmacology lectures. More respondents generally prefer lectures on clinical pharmacology or therapeutic cases $(65.7 \%)$ followed by basic pharmacology or illustrative cases $(19.6 \%)$ and the least was historical perspective or discoveries in 
pharmacology $(3.2 \%)$. More females prefer clinical pharmacology $(64.2 \%)$ and discoveries $(7.5 \%)$ compared with the males $(61.3 \%$ and $0.7 \%$ respectively). On the other hand, more males prefer research or evidence-based cases (13.0\%) and basic pharmacology (19.0) compared with the females (6.7\% and $17.9 \%$ respectively), with all being far below average. There was significant difference in preferences between males and females and between observed and expected results $\left(\chi_{\mathrm{df}=3}^{2}=17.2191, \mathrm{p}<0.05\right)$.

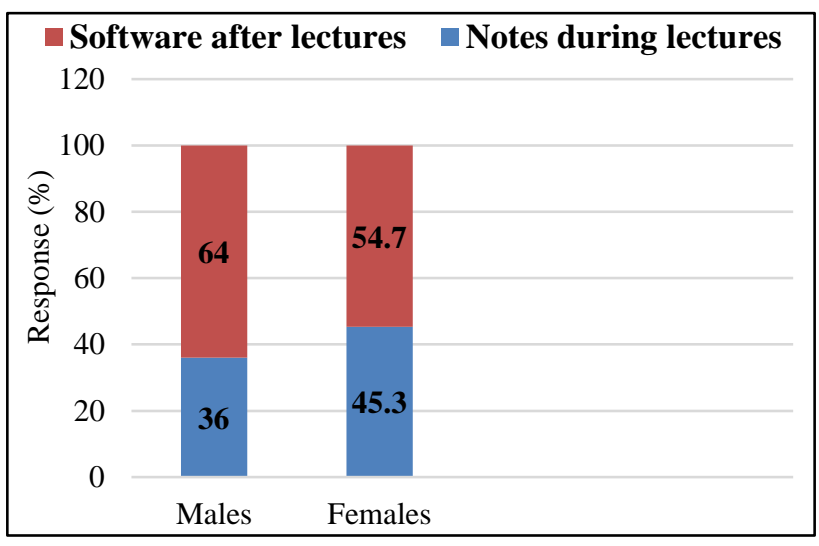

Figure 2: Preference FOT types of lecture notes among males and females.

\section{Preference for some pharmacological information on drug profile}

Table 5 shows the result on opinions of students on some preferred information on drug profiles in pharmacology lectures. Most respondents generally prefer information on pharmacodynamics of the drug $(59.0 \%)$ compared with pharmacokinetics $(38.0 \%)$. A total of 12 respondents (3.0\%) defaulted with either no or multiple responses that could not be analyzed. Females (40.3\%) prefer pharmacokinetics more than the males $(36.8 \%)$. Both preferences for pharmacokinetics were below average $(50 \%)$ for either females or males. In like manner, more females $(57.5 \%)$ prefer pharmacodynamics compared with the males $(59.9 \%)$, with both being above average. There was no significant difference in preferences for information on pharmacokinetics and pharmacodynamics between males and females and between observed and expected results $\left(\left(\chi_{\mathrm{df}=1}^{2}=0.4341, \mathrm{p}>0.05\right)\right.$.

Table 5: Preferred type of information on drug profile.

\begin{tabular}{|lllll|}
\hline Drug Profile & Females & Males & Total & $\%$ \\
\hline Pharmacokinetics & $\begin{array}{l}54 \\
(40.3)\end{array}$ & $\begin{array}{l}99 \\
(36.8)\end{array}$ & 153 & 38.0 \\
\hline Pharmacodynamics & $\begin{array}{l}77 \\
(57.5)\end{array}$ & $\begin{array}{l}161 \\
(59.9)\end{array}$ & 238 & 59.0 \\
\hline Default & $3(2.2)$ & $\begin{array}{l}9 \\
(3.3)\end{array}$ & 12 & 3.0 \\
\hline Total & 134 & 269 & 403 & 100 \\
\hline
\end{tabular}

Values in parenthesis are \% based on gender for each option

\section{Opinions on some preferred knowledge during a pharmacology lecture}

The results on some preferred knowledge on pharmacology during lectures are shown on Figures 4 and 5.

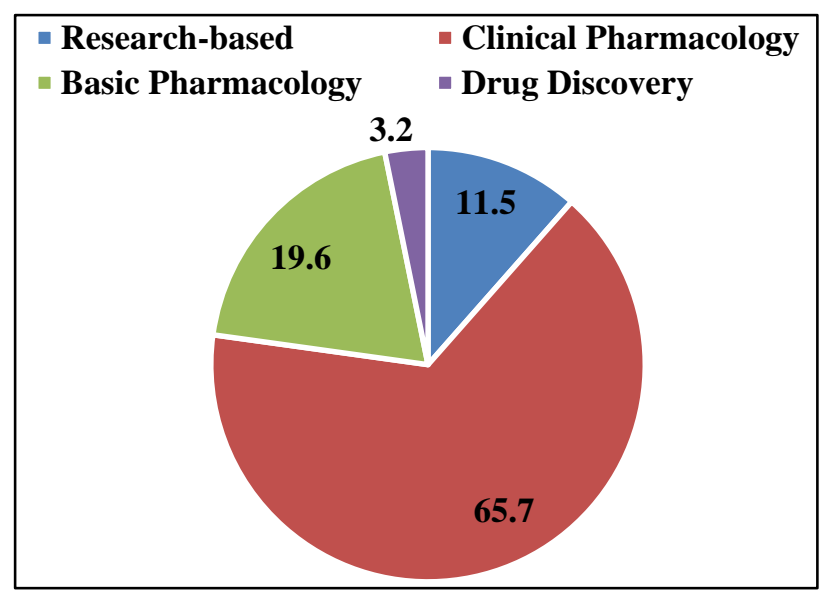

Figure 3: Responses on preferred scope of pharmacology lectures.

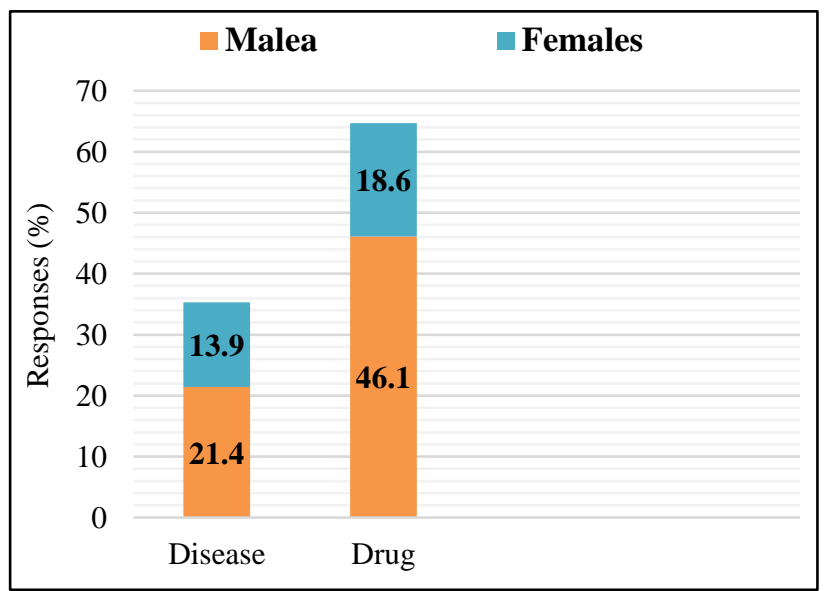

Figure 4: Preferred knowledge in pharmacology.

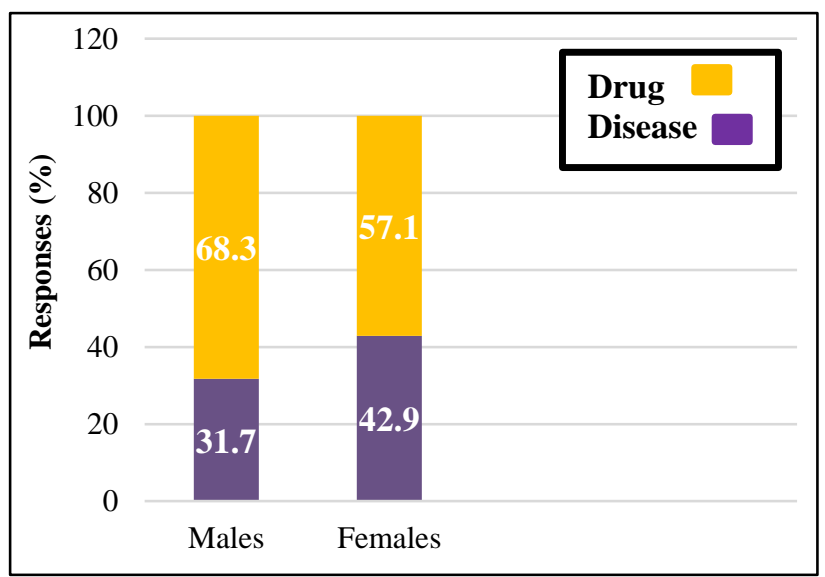

Figure 5: Preferred knowledge in pharmacology among males and females respondents. 
The results showed that the students prefer knowledge on profiles of drugs $(64.7 \%$, consisting of $46.1 \%$ males and $18.6 \%$ females) than pathophysiology $(35.3 \%$, consisting of $21.4 \%$ and $13.9 \%$ males and females respectively). A total of $15(3.7 \%)$ respondents defaulted by reason of blank response or multiple choices. More females (42.9\%) preferred knowledge on the disease compared with the males $(31.7 \%)$, while more males $(68.3 \%)$ preferred knowledge on the drug compared with the females $(57.1 \%)$. Generally, there was significant difference in preferences between males and females and between observed and expected results $\left(\chi_{\mathrm{df}=1}^{2}=6.6956, \mathrm{p}<0.05\right)$.

\section{DISCUSSION}

Teaching is a dynamic profession that requires constant appraisal and adjustments. The results from this study revealed two important findings. Firstly, the need to evolve more teaching methods and depart from the current traditional ones in teaching of pharmacology and secondly the importance of feedback responses from the students in order to improve their learning and understanding of the subject matter.

The current admission policy into tertiary institutions in Nigeria appears in favor of the male and this may perhaps explain the reason for more males than females among the participating students on this study.

The respondents generally demonstrated a good sense of clarity on their preference of given options, except for the few default or invalid cases. However, when put into proper perspective for specific options as expected in this study, there were contradictions that appear to be of concern on the general understanding of the respondents regarding the interrelationships of the options to knowledge of pharmacology that have relevance in learning of the subject matter. That 143 (36.2\%) respondents showed preference for power point in pharmacology lectures as against $241(61.0 \%)$ respondents that prefer taking software after lectures is a contradiction because power point is a form of software. In the same vein, even though $254(63.3 \%)$ respondents showed preference for 2 hours lecture, $228(61.8 \%)$ prefer practical sessions. However, practical sessions in the school last 3 hours, which only $4(1.0 \%)$ respondents showed their preference for it. It is obvious that the students don't prefer lecture sessions beyond 2 hours. Again, while 238 (60.9\%) respondents and $251(65.7 \%)$ showed preference for "pharmacodynamics" of drugs and "clinical" components in pharmacology, only 137 (35.3\%) prefer the component that deals with some information on pathophysiology of diseases. However, for a good understanding and knowledge of pharmacodynamics and clinical pharmacology which deal essentially with mechanisms by which drugs act, some basic knowledge of pathophysiology of diseases is required for such good understanding. This is an evolving knowledge different from the current traditional setting of teaching pharmacology that was mainly based on basic concepts.
Indeed, for a proper knowledge of pharmacology, students must be informed from the beginning that all components of pharmacology must be considered holistic for an effective learning and understanding of the subject. ${ }^{11}$ However, this study revealed that more of the students prefer clinical pharmacology $(65.7 \%)$ compared with areas such as basic pharmacology (19.6\%), historical discoveries of drugs $(3.2 \%)$ or research-based cases $(11.5 \%)$. These were found to be significantly different between the males and females $(\mathrm{p}<0.05)$ suggesting the reality of such preferences. This may perhaps have implications on the learning differences in pharmacology between males and female students. Preference for dictating notes during lectures was $5 \%$ but that for taking notes during lectures was higher $(39.0 \%)$. This is a contradiction that can hardly be reconciled except the students interpret the options differently, because taking note during lectures is strongly tied to dictating the note. Preference for combination of all the teaching methods was $57.0 \%$, but how all the methods can be combined during a lecture session remains to be understood. The lecturers currently employ different teaching aids and methods and perhaps this may informed the reasoning of the students. However, students were expected to demonstrate clear thinking and reasoning skills which are expected in learning and understanding of pharmacology.

Preference for clinical pharmacology was highest among all the options used for this assessment $(65.7 \%)$ while the "3-hour" lecture session was the lowest (1.0\%). The males showed the highest preference on their choice for knowledge of drug profiles $(68.3 \%)$ while the females had their highest preference on their choice for combination of all teaching methods $(67.4 \%)$. On the other hand, the males had their lowest preference on the option on 3-hour lecture session $(0.7 \%)$ while the females showed their lowest preference on the option on blackboard notes $(0.8 \%)$.

Though all components of pharmacology are important, emphasis on the clinical aspect and practical sessions when developing pharmacology curricula should be encouraged because pharmacology is essentially a medical science useful to all health-based professionals. . $^{3,9}$

\section{CONCLUSION}

In conclusion the findings from this study point to the fact that the teaching methods in pharmacology are dynamic with high preference of the latest technological teaching aids such as power point presentation and use of software as lecture materials. These findings will further serve as guides for pharmacology tutors towards improvement on the learning and understanding capacity of the students for effective management of patients during drug therapy.

\section{ACKNOWLEDGEMENTS}

Authors would like to thank Messrs, Daniel Bulus and Victor Taptu Lere for their kind assistance in the area of administration of the questionnaires to the students. 
Authors also remained indebted to the students for their kind cooperation during the exercise.

Funding: No funding sources

Conflict of interest: None declared

Ethical approval: The study was approved by the Institutional Ethics Committee

\section{REFERENCES}

1. Saroyan A, Sneill L. Variations in teaching styles. Higher Educ. 1997;33:85-104.

2. Tikoo D, Gupta M, Geeta S. Student feedback on teaching-learning methodology and evaluation methods in pharmacology. Int. J. Basic Clin. Pharmacol. 2015;4(6):1260-6.

3. Barry OP, Sullivian EO, McCarthy M. Periodic review sessions contribute to student learning across the disciplines in pharmacology. J. Sch. Teaching. Learning. 2015;15(1):38-56.

4. Westwood P. What teachers need to know about teaching methods, Camberwell, Vic., Australian Council for Education Research (ACER) Press, Australia; 2008.

5. Chulwant KS. Comparison of two teaching methods, structured interactive lecture and conventional lectures. Biomed. Res. 2012;23(3):363-6.

6. Rogers KM. A feasibility study on the development and integration of teaching aid for pharmacology. Int. J. Modern Educ. Forum. 2012;1(2):53-6.

7. Achike FI, Ogle CW. Information overload in the teaching of pharmacology. J. Clin. Pharmacol. 2000;40(2):177-83.

8. Natu MV, Sigh T. Objective structure practical examination (OSPE) on pharmacology students' point of view. Indian J. Pharmacol. 1994;26:188-9.
9. Shefield GM. Integrating clinical pharmacology teaching with general practice. Br J Clin Pharmacol. 1998;45:399-401.

10. Hosseini DR. How to use power-point effectively. Educ. Stat. Med, Sci. 2008;1:2-10.

11. Zgheib NK, Simoan JA, Sabra R. Using team-based learning to teach pharmacology to second year medical students improves student performance. Medical Teaching 2010;32(2):130-5.

12. Eteraf-Oskouer T, Najafi M. The effective teaching method of pharmacology for the students in the Faculty of Health and Nutrition in Tabrez University of Medical Sciences. Res. Dev. Med. Educ. 2013;2(1):7-11.

13. Lloyd H, Hinton T, Bullock S, Babey AM, Davis E, Fernandes L, et al. An evaluation of pharmacology curricula in Australian Science and Health-related degree programs. BMC. Med. Educ. 2013;13:153-67.

14. Mathur VS. Towards a more meaningful teaching of pharmacology. Indian J Pharmacol. 2004;36:259-61.

15. Garg A, Rataboli PV, Muchandi K. Students' opinion on the prevailing teaching methods in pharmacology and changes recommended. Indian J. Pharmacol. 2004;38(3):155-8.

16. Badyal DK, Bala S, Kathuria P. Student evaluation of teaching and assessment methods in pharmacology. Indian J. Pharmacol. 2010;42(2):87-9.

Cite this article as: Bukar BB, Falang KD, Gyang SS. Assessment of undergraduates' preferences and opinions on teaching of Pharmacology. Int J Basic Clin Pharmacol 2018;7:215-20. 